\title{
¿UNA MÉTRICA DE NUEVA PLANTA? MÉTRICA Y TEORÍA DE LA LITERATURA
}

\author{
José María Paz Gago \\ Universidade da Coruña
}

\section{INTRODUCCIÓN}

Una deficiente transmisión de la doctrina (pseudo)clasicista, la tradición escolar y el positivismo decimonónico consagraron una persistente concepción preceptivista de la Métrica, concepción que ha llegado hasta nuestros días. Supeditada a las Artes Retóricas destinadas a la enseñanza o a una Gramática con una funcionalidad no menos estrictamente pedagógica, la Métrica se ha venido entendiendo como conjunto de técnicas de versificación, de aplicación más o menos mecánica, como repertorio de reglas y licencias o como aparato taxonomizante que ofrecía categorías clasificatorias por doquier. Los análisis críticos de la poesía se han limitado con frecuencia a la mera descripción de esos procedimientos métricos y a las consabidas tipologías (de acentos, de versos, de estrofas, de poemas) pero a poco o a nada más. 
La necesidad de dar un sustrato teórico-crítico a los estudios métricos ha chocado contra esos escollos de manera tan pertinaz que ni los intentos más ambiciosos de lograr una teoría métrica sólida han podido llegar a buen puerto o, cuando menos, no han tenido la esperada continuidad y, por tanto, no han hecho realidad la esperada revolución definitiva del análisis métrico de la poesía lírica. Desde un punto de vista epistemológico parece evidente que la Métrica Teórica debe vincularse a la Teoría de la Literatura y a la Poética, integrándose y formando parte de ellas, así como la Métrica Descriptiva se incarnará en la Crítica Literaria. La Métrica Comparada, tan frecuentada por los formalistas eslavos, constituirá un subdominio privilegiado de la Literatura Comparada, de igual forma que la Métrica Histórica debería constituir un subdominio en el campo de la Historia de la Literatura.

Pero lo ciertro es que ni siquiera la radical renovación de los estudios literarios que protagonizaron los Formalistas Rusos en el primer cuarto de siglo superó esa tendencia de vincular la Métrica a lo didáctico y a lo preceptivo. Aunque esta Escuela sentó las bases de una ciencia literaria cabalmente científica, el Formalismo estableció una Teoría general del verso (Eichenbaum 1925), una Teoría del lenguaje poético (Jakobson), en cuyo seno se reserva a la Métrica un papel de disciplina auxiliar, de carácter eminentemente propedéutico.

En las décadas centrales de esta centuria tan rica en planteamientos críticos, la Estilística apenas superó las interpretaciones preceptivistas denunciadas más arriba y sus bases neoidealistas no aportaron más revisión teórica que los aspectos del fonosimbolismo, interpretados en clave impresionista. Habrá que esperar a los años cincuenta para asistir al nacimiento de las teorías métricas vinculadas, excesivamente en este caso, a las grandes teorías linguiísticas hegemónicas en la época. Entroncadas directamente con el Formalismo de la Europa Oriental, surgen de la mano de Roman Jakobson, John Lotz y Morris Halle la métrica estructuralista primero y la métrica generativa poco después.

Quizás surja de ahí uno de los mayores problemas de estas propuestas de cierto alcance en la renovación de las teorías métricas, el estar excesivamente supeditadas a los modelos lingüísticos que las inspiraron. La descripción del verso, en el contexto teórico del generativismo lingüístico, se fundamenta en los rasgos fonológicos y fonéticos de la lengua ordinaria, con respecto a los cuales los fenómenos métricos no constituirían un desvío, sino un uso más. Esta nueva Métrica, en efecto, se adaptaba a la fonología transformacional, adoptando tanto sus unidades entonativas y melódicas como la modalidad de representación para la 
estructura acentual de los versos, según la configuración arbórea típicamente transformacional. Carlos Otero Pelegrín (1981: 319) invertía esta estrecha relación interdisciplinar al caracterizar la Fonología generativista como de índole métrica, en cuyo seno el acento no sería concebido como propiedad de la vocal sino como la prominencia relativa entre sílabas contiguas o entre pies contiguos. La teoría fonológica chomskyana habría redescubierto el concepto (métrico) de pie o secuencia de sílabas, y a ello no sería ajena la colaboración de Morris Halle, creador de la métrica generativista.

También en estos contextos, de todos modos, la métrica sigue siendo una disciplina literaria ancilar y desprestigiada, la menos desarrollada y la que más dificultades presenta, pues ni lo métodos de estudio ni su orientación están claros. Para el caso de la Métrica Estructural, Seymur Chatman y Samuel R. Levin eran de lo más expresivos y contundentes en 1973, cuando sentenciaban metafóricamente: For centuries metrics has been the great bête noire of literary studies, enumerando las razones de esta curiosa resistencia de los estudios literarios a resolver los desafíos significativos planteados por los fenómenos rítmicos y métricos: falta de adecuación del método, falta de habilidad para definir los términos o para establecer una terminología mínima, confusión entre los sistemas fonológicos de las distintas lenguas (griego, latín, inglés), confusión con otras artes como la música, inadecuación de las presuposiciones psicológicas... (1973: 253).

Pese a los abundantes trabajos sobre métrica generativa surgidos en el entorno del MIT, especialmente las aportaciones de Halle y Keyser, uno de los introductores de la Poética Generativa en Europa, Jean Jacques Thomas, evadía de nuevo la problemática y terminaba la introducción a su artículo sobre «Teoría Generativa y Poética Literaria», publicado en el número 51 de la revista Langages, con esta sorprendente nota aclaratoria: Se han dejado de lado las discusiones sobre «métrica generativa» por razones teóricas (?) y prácticas (1989: 12), las primeras nos remiten a un futuro estudio más general y las segundas se refieren a las peculiaridades de la métrica inglesa que, como ya sugerían Levin y Chatman, dificultarían la extensión de tal modelo teórico a la poesía francesa o española.

Al plantearse el problema que aquí trato de abordar, Domínguez Caparrós recurría a la Semiótica en tanto que Teoría general de la literatura como el marco teórico ideal para replantear la función y enunciar las consecuencias significativas, comunicativas y estéticas de la Métrica. En ese trabajo fundamental de mediados de los ochenta, uno 
de los máximos especialistas en teoría métrica reconocía que no existía ninguna obra de conjunto que enfocase los problemas del verso como hechos de comunicación y echaba en falta una sistematización en el estudio del papel de la métrica como una de las convenciones de la comunicación artística poética (1985 en 1999: 20). Ese será, como veremos, el camino que me propongo tomar, no sin antes pasar revista a los intentos más consolidados de dar fundamentación teórica al análisis métrico de la poesía.

\section{MÉTRICA Y TEORÍA LITERARIA DEL FORMALISMO RUSO}

Dentro de su particular y valiosísima renovación de la Poética, los formalistas rusos fueron los primeros en ofrecer una reinterpretación de la función y el significado de los procedimientos métricos explotados por la poesía lírica, en las primeras décadas del siglo. Aspecto formal por excelencia, será en los Círculos formalistas de Petrogrado primero y de Moscú después donde se inicie la consideración de los aspectos rítmico-métricos en el contexto de la teoría del lenguaje literario.

Las convenciones rítmicas y métricas entran, para los formalistas, en los fenómenos que ellos consideran como repetición, y de este principio general que explica la poesía surgirá tanto su valor poético propio como su función estética fundamental. Es esta idea del valor estético autónomo de las repeticiones de sonidos en la poesía la que aparece ya antes de los años veinte. En la primera publicación de los miembros del OPOJAZ, su Sborniki po teorii poeticheskogo iazyka, I, (Publicaciones sobre la teoría del lenguaje poético), editado en San Petesburgo en 1916, se afronta esa cuestión polémica que enfrenta a los jóvens formalistas y futuristas con los críticos simbolistas imperantes hasta entonces.

Lev Iakubinski en su trabajo «Sobre los sonidos del lenguaje poético», Viktor Shklovski en «Sobre la poesía y el lenguaje transracional», o el conocido trabajo de Osip Brik «Las repeticiones de los sonidos», aparecido en el segundo volumen del Círculo de Petrogrado (1917), a los que hay que añadir «Sobre los sonidos en el verso», de Boris Eichenbaum, de 1920, expresaban esta nueva concepción de los recursos métricos que este último sintetizaba en su célebre exposición de la 
teoría del método formal: La conclusión natural de todas estas observaciones y principios fue que el lenguaje poético no es únicamente un lenguaje de imágenes y que los sonidos en el verso no son únicamente elementos de una eufonía exterior, es decir, no sólo acompañan al sentido, sino que tienen un valor autónomo (1925 en Volek ed. 1992: 79).

La contundencia de sus posiciones antisimbolistas convierte a Eichenbaum en uno de los grandes refundadores de la métrica contemporánea al afirmar que los sonidos en el verso poseen una función discursiva autónoma (Ibidem). En palabras de su amigo Brik, refiriéndose concretamente a las rimas consonantes, estas coincidencias fónicas no son únicamente un apéndice eufónico, sino el resultado de una aspiración poética autónoma (1917 en Volek ed. 1992: 80).

El mejor conocedor y sistematizador de las teorías métricas del Formalismo Ruso, el profesor español José Domínguez Caparrós (1988, 1999), ha expuesto las bases para una fundamentación de los estudios métricos en la teoría literaria de los formalistas que, ya en la década de los veinte, se ocuparon de ellos con mayor intensidad y brillantez, tales como Eichenbaum $(1922,1925)$, Tomachevsky $(1923,1924)$, Tynianov (1924), Zhirmuskij (1921, 1925) o Jakobson (1923, 1933, 1935).

Al afrontar los problemas de la métrica y del ritmo, Eichenbaum pone de relieve la necesidad de plantear el problema del ritmo independientemente de la métrica, como un fenómeno de discurso poético. Evocando los célebres trabajos de Osip Brik sobre las figuras rítmicosintácticas («Ritmo y sintaxis», 1927), dejaba sentada la concepción lingüística de los procedimientos rítmicos. Jakobson, por su parte, insistirá desde esos años moscovitas en la idea de la correspondencia total entre la lengua ordinaria y la lengua poética, por lo que considera el verso como un fenómeno lingüístico y los procedimientos rítmico-métricos como procedimientos sintácticos y fonéticos.

Es éste uno de los principios generales claves en el que todos los formalistas citados están de acuerdo: El ritmo no es un problema puramente métrico sino que en él participan factores sintácticos y entonativos, por lo que se ve la necesidad de ampliar esta noción a todos los elementos lingüísticos que intervienen en la construcción del verso (Eichenbaum 1922, Tomachevski, 1923, Tinianov 1924). Además, dado que sus consecuencias son también significativas, el ritmo debe ser tenido en consideración también por la Semántica Poética, cuyo objeto serían las cualidades semánticas del discurso poético (Tynianov 1924, Eichenbaum 1925). 
Sintetiza Eichenbaum de forma admirable lo que va a ser este trascendental replanteamiento de los estudios del ritmo y de la métrica protagonizado por el Formalismo Ruso, que instituye una Teoría de la lengua poética cuyo objeto será el ritmo como base constructiva del verso y como determinante de todos los aspectos que intervienen en su configuración, tanto los aspectos fónicos y acústicos como los sintácticos y semánticos. Se fundamenta de este modo una Teoría general del verso dentro de la cual la Métrica ocupará el lugar, dice el autor de la «Teoría del método formal», de una propedéutica elemental (1925, Volek ed. 1992: 95).

De Eichenbaum a Jakobson, queda clara la concepción formalista de los fenómenos métricos como fenómenos de naturaleza linguística $\mathrm{y}$, por tanto, la ubicación de la Métrica como un subdominio de la Poética o ciencia de la lengua poética. Lo que interesa primordialmente en este contexto teórico es el estudio del discurso poético y los principios generales que definen su poeticidad, entre los que se encuentra el principio de recurrencia, identificado con los factores rítmicos más que métricos. Por esta razón, tal como afirma Eichebaum axiomáticamente, La métrica se retiró a un segundo plano, conservando el valor de alfabeto del verso.

Los lastres del didactismo y la aplicación mecanicista a la enseñanza de la literatura tampoco fueron abandonados por los Formalistas rusos que prefirieron centrar sus estudios en los fenómenos paralelísticos y rítmicos en general, reservando como siempre a la métrica una función puramente propedéutica.

\section{MÉTRICA ESTRUCTURAL Y MÉTRICA GENERATIVA}

Desde principios de los años cuarenta, Lotz propugnaba un análisis métrico estructural (1942), que aplicará a la poesía eslava desde el punto de vista de la Métrica Comparativa en colaboración con Jakobson (Lotz y Jakobson 1952, Jakobson 1952), para culminar en la consolidación de la Métrica estructuralista en el célebre Congreso de Indiana sobre Estilo en el lenguaje, celebrado en 1958 (Sebeok ed. 1960). En el trascendental foro de Bloomington, Lotz propondrá una ambiciosa tipología métrica de acuerdo con las diferentes lenguas en las que se articulan los distintos sistemas de versificación 
(1960b) ${ }^{1}$ mientras que Jakobson asocia la nueva propuesta a la doctrina formalista, definiendo el verso, tal como lo había hecho en los años veinte y treinta, como un fenómeno esencialmente lingüístico además de poético (1960: 365).

Los trabajos de Whitehal y Hill (1951 y 1958) desarrollan la concepción de un sistema métrico de cuatro acentos, que es contrastado con análisis de numerosos textos poéticos ingleses. Partiendo del paralelismo con el sistema lingüístico de la lengua inglesa, caracterizada por cuatro grados de acento fonético, llegan a la conclusión de que el acento lingüístico primario es métricamente fuerte (strong), el acento lingüístico débil es métricamente débil (weak) y los acentos con función secundaria y terciaria serán métricamente fuertes o débiles según el contexto.

Lo más interesante de este intento de crear una métrica de nueva planta, basada en la poderosa Fonología estructural, es su temprana y eficaz aplicación crítico-literaria. En efecto, los principales impulsores de esta renovada atención a los sistemas de versificación, directamente inspirada en las tempranas aportaciones del Formalismo Ruso ya reseñadas, llevaron a cabo un desarrollo efectivo del análisis métrico, con evidentes repercusiones en la renovación de la Crítica literaria estructuralista, conocida como Poética estructural, en conexión nada desdeñable con la estilística lingüístico-literaria norteamericana. Chatman, Fowler, Hollander o Levin no dudaron en aplicar sus investigaciones métricas a una gran variedad de textos poéticos para sacar conclusiones sobre calidad poética y estilo literario.

En línea con las tesis del Formalismo eslavo, Chatman (1965: 5673) integra en la teoría del metro los sistemas tanto acentuales y entonativos como rítmicos, utilizando una concepción psicologista del ritmo. Distingue entre el hecho métrico (event), que sería la sílaba, y la prominencia (prominence), la cual radica unas veces en el acento lingüístico y otras en el acento métrico, o en la misma tensión del sistema métrico. El análisis métrico, que Chatman aplica a los sonetos de Shakespeare, consistirá en analizar las escansiones versales definidas por la reducción del dato lingüístico que opera el sistema métrico en la ejecución. En un trabajo de título tan revelador como «What is

1 Distingue Lotz 5 tipos métricos: silábico puro (pure syllabic), propio de la poesía eslava, y silábico-prosódico (syllabic-prosodic), duracional (durational), explotado en el griego clásico, dinámico (dynamic), propio del verso inglés, y tonal (tonal) el sistema característico de la poesía china. 
Metrical Analysis?», profundiza Fowler en este aspecto crítico-estilístico que tanto interesó a los investigadores y practicantes de la Métrica Estructural, preocupados en describir y definir las unidades y fenómenos pertinentes, es decir, realmente relevantes para el estudio métrico (1968: 281-282 y 1966a) y con una funcionalidad formal pero también significativa y estilística. No en vano, ya antes de exponer su teoría métrica, Chatman (1960) había tratado de utilizar la métrica estructuralista como base para un análisis comparativo de los estilos poéticos.

Esas Poéticas estructuralistas que emergieron con tanta fuerza en los años sesenta trataron de dotar a la métrica de una base teórico-crítica adecuada, y lo hicieron en consonancia o paralelamente a la Poética Generativa, que protagonizó el proyecto teorético más serio e innovador de crear lo que Carlos Peregrín Otero, estrecho colaborador de Noam Chomsky, llamó una Métrica de nueva planta (1981). No sólo no fueron antagónicos las propuestas métricas de estructuralistas y generativistas, sino que ambas compartieron en sus inicios perspectivas teóricas y aplicaciones prácticas. Autores como Freeman (1968, 1969) o Beaver $(1968,1969)$ trataron de utilizar el modelo de Halle y Keyser para dilucidar las cuestiones de estilo métrico y poético, y el segundo lo hizo perfectamente compatible con la teoría métrica estructuralista de Chatman. Si el mismo Levin milita en las dos corrientes, el punto de contacto entre uno y otro proyecto de formular la métrica desde los postulados de las respectivas teorías lingüísticas fue la figura singular de Morris Halle que si en 1956 publicaba con Jakobson los Fundamentos del Lenguaje, una docena de años más tarde sentaba con Chomsky las bases de la fonología generativa del inglés (1968), sustrato esencial de la métrica generativa que había expuesto con su inseparable Jay Keyser en 1966.

Las bases teóricas de la métrica generativista tal como fueron expuestas por Halle y Morris para el verso inglés tanto antiguo como moderno, dieron lugar a una orientación bien definida en los estudios métricos que generó en un primer momento una abundante y desigual bibliografía, constituída por aplicaciones, revisiones o matizaciones a las premisas fundacionales: Beaver $(1968,1969,1974)$, Freeman (1968, 1969), Hascall (1969, 1974), Wimsatt (1970), Levin (1973, 1976), Gueron (1974), Bowley (1974), Klein (1974), Ihwe (1975).

Esta inicial Métrica generativa de Halle y Keyser (1966) parte del concepto básico de acento métrico máximo, aquel acento fuerte que siempre irá precedido y seguido por dos acentos débiles, de modo que si este acento se da en una posición débil, debe considerarse como 
amétrico. En efecto, los versos que no cumplen el principio del stress maximum son caracterizados como amétricos. Keyser aplicará esta primera versión a la poesía inglesa antigua (1969b) y moderna (1969a), introduciendo modificaciones y restricciones como aquella en virtud de la cual los acentos laterales débiles deben estar en el mismo constituyenye sintáctico que el acento fuerte central.

Resulta de especial interés la explotación de este primer modelo, de naturaleza fundamentalmente prosódica, como criterio crítico-literario por parte de la Poética y la Estilística Estructural. Así, Beaver combina las teorías métricas de Halle-Keyser y Chatman para establecer cinco tipos de configuraciones silábicas según la función realizada por el acento máximo en cada una de ellas. En su opinión, la densidad relativa y la distribución de los stress maximum puede servir para establecer diferentes estilos métricos y para valorar la calidad rítmica de versos y poemas. Lo mismo hará Freeman que extiende el principio posicional del acento a las licencias métricas y propone hacer uso de él para caracterizar diferentes estilos métricos, según las lenguas, las épocas y los poetas. Ambos autores continúan preocupados por el análisis métrico, tratando de discernir las posibilidades analíticas del acento máximo para lo que profundizan en su naturaleza — si es léxico o frástico, si tiene un estatuto contrastivo- y en la de los acentos secundarios.

A la luz de estas reflexiones surgió también un interesante intento de reformulación de los estudios métricos sobre poesía hispánica en la primera mitad de la década de los ochenta: para el caso de la lírica castellana, Carlos Piera (1978 y 1981) replantea desde esta nueva perspectiva teórico-lingüística el estudio del verso español, tal como había hecho ya Núñez Ramos (1978) al ofrecer un interesante modelo abstracto del endecasílabo aúreo; las mismas intenciones persigue Salvador Oliva (1980) para el verso catalán y Domingos Prieto Alonso (1983, 1984 y 1986) para el caso de la rica tradición lírica gallega.

En el trabajo más ambicioso y abarcador, Piera muestra una escrupulosa fidelidad a los principios epistemológicos típicamente transformacionalistas, de acuerdo con los cuales lo que interesa es establecer los principios generales de las pautas métricas. De acuerdo con el rígido deductivismo chomskyano, se trata de enunciar un modelo métrico abstracto, sílabo-acentual en el caso del verso castellano, teniendo presentes los resultados alcanzados en los abundantes trabajos ya reseñados sobre el verso inglés, para el que precisamente se había creado el modelos teórico de Halle-Keyser. 
La razón de ser de la métrica deja de ser la simple descripción de versos y estrofas, de composiciones poemáticas y las licencias en ellas explotadas, para centrar el interés de esta renovada disciplina en la formulación de principios teóricos que subyacen a y dan cuenta de las realizaciones particulares. Se trata ahora de enunciar reglas métricas y principios del cómputo silábico, como el principio del acento máximo de Halle-Keyser, considerado como un principio exclusivamente negativo por Wimsatt (1970).

El entusiasmo que provocó en la teoría literaria española de finales de los setenta y principios de los ochenta esta nueva forma de afrontar el problema del metro y el ritmo no era disimulado por Núñez Ramos (1978: 157) cuando afirmaba que la métrica generativa suponía el paso definitivo hacia la constitución de una teoría métrica propiamente dicha, esto es, general y abstracta. Reivindicando las tan manidas nociones de estructura profunda y estructura superficial, competencia y ejecución, como conceptos operacionales en virtud de su elevado grado de abstracción, las variantes acentuales de los versos se explicarían como realizaciones de superficie de una estructura métrica subyacente.

El monumental trabajo doctoral de Piera, que nunca ha podido ver la luz (editorial), también era comentado por Otero con optimismo desbordado pero no exento de cautela: Aunque adelantarse al juicio de la historia tiene sus riesgos, me atrevería a decir que acaba de ser inaugurado un nuevo periodo en las investigaciones métricas (1981: 319). Ese cauto comienzo se reveló lo más profético de tan entusiasta declaración, a la que la historia invocada no pudo dar la razón.

Esta teoría general de la métrica debe ser capaz, en primer lugar, de predecir qué versos son realizaciones de una pauta métrica determinada, concebida como una unidad abstracta, subyacente, y no observable en la secuencia, superficial y audible, de sonidos del verso. En segundo lugar, debe permitir la evaluación de la variabilidad o complejidad métrica (tensión), enunciando reglas generadoras de pautas métricas, reglas prosódicas y reglas métricas. Bien entendido que esa variabilidad es un atributo de la ejecución de tal o cual verso y no una propiedad intrínseca de la pauta.

Obviedades de la escolástica generativista, carecerá de complejidad, de tensión, aquel verso que no se devíe en absoluto de la pauta métrica y tendrá una complejidad o tensión extrema el que más se desvíe, quedando en medio los versos de tensiones intermedias. Una perspectiva desviacionista más, el rigorismo transformacional no abandona su 
temprano contacto con la Estilística estructuralista y sus conclusiones siguen situándose en esa órbita crítica: en opinión de Piera y de Otero (1981: 314), en efecto, esta escala de compeljidad métrica podría servir, al menos en algunos casos, para evaluar la modernidad de una composición (?): un poema en el que no se da correspondencia entre los acentos de las palabras y el acento máximo de la pauta métrica sería modernísimo, y si además se produce encabalgamiento, aumentaría la tensión entre verso y pauta métrica.

Aunque los presupuestos del generativismo quisieron distanciarse explícitamente de conceptos estilísticos y formalistas como el desvío o la desautomatización para explicar la lengua literaria, es indudable que los fenómenos métricos responden en cierto modo a esos mecanismos formales explotados por el lenguaje poético con unas consecuencias significativas, estéticas y comunicativas innegables. En ese sentido apuntaban las conclusiones de Núñez Ramos cuando describía los tipos desviados respecto al modelo abstracto del endecasílabo gongorino por él construido: esos versos anómalos no eran para el investigador ovetense gratuitos, pues poseen efectos estilísticos innegables ya que la ruptura del esquema acentual sirve para destacar el verso en que se produce y, al favorecer la desautomatización y evitar la monotonía, determina una percepción estética más consciente y elevada (1978: 163).

No en vano, Núñez Ramos da este giro pragmático a la teoría métrica generativista al vincularla a la noción de ritmo o efecto de la realización efectiva de las leyes métricas. Para dar cuenta de los efectos estéticos del metro y el ritmo evoca precisamente las aportaciones del formalismo ruso (Brick, Tynianov) y de la Poética estructuralista (Chatman, Levin) que están en la base de la Semiótica y la Pragmática de la poesía, los contextos adecuados para analizar el papel comunicativo y estético de los procedimientos métricos y rítmicos.

En su evolución hacia el fin de siglo, la Métrica generativa no sólo no consiguió satisfacer las necesidades teóricas del análisis poético y los anhelos renovadores de la Poética moderna, sino que se quedará en una mera disciplina gramatical y fonológica, alejándose definitivamente de los dominios propios de la ciencia literaria y de la teoría y crítica de la poesía lírica. La teoría métrica del acento, tal como la exponen Morris Halle y Vergnaud a principios de la década de los noventa, se centra en una propuesta formal y abstracta de la estructura del constituyente métrico, en su construcción y representación, como modelo altamente formalizado para describir la gramática acentual de las más 
diversas lenguas (1990: 139-180). En esta obra de la que curiosamente desaparece el nombre de Keyser, en efecto, se aplica desde un punto de vista estrictamente lingüístico el modelo descriptivo y representacional del acento principal (main stress) y de los acentos secundarios, así como el sistema de reglas que rigen su uso, al inglés (1990: 227-276) y a una amplia nómina de lenguas clásicas y modernas, indoeuropeas y amerindias, el árabe y el hebreo, caucásicas y africanas. La bibliografía producida en este tiempo sobre Métrica generativa se reduce a los trabajos de investigación y a las tesis doctorales que dirige en el Instituto Tecnológico de Massachusets Morris Halle con este preciso enfoque metodológico (B. Hayes, J. Levin, P. Kiparsky), y a algunos trabajos circunstanciales realizados en los últimos años por el propio Halle sobre poesía rusa (1985a y 1985b) o sobre poesía hebrea clásica, los salmos en concreto (1997b), amén del artículo que, un cuarto de siglo después, dedicó en colaboración con Keyser al verso yámbico inglés (1998).

Una última palabra sobre la métrica francesa de corte transformacional nos servirá para introducir la siguiente sección. En efecto, a principios de los setenta, en los estudios de métrica francesa se dan cita simultáneamente la tradición estilística tan propia al mundo académico galo, la tendencia estructuralista imperante y las propuestas generativistas importadas de América. Desde la perspectiva de una estilística modernizada, Pierre Guiraud (1970: 64) abría la década distinguiendo entre una Gramática Métrica, la parte propiamente descriptiva en tanto que inventario de las formas métricas pertinentes y sus reglas de empleo, y una Métrica Retórica a la que corresponderían los efectos rítmicos y métricos propiamente dichos, los que más van a interesar a la perspectiva teórica actual.

En consonancia con algunos principios transformacionales y con la tendencia más persistente, lo que se busca es precisar los rasgos fundamentales de esa Gramática Métrica del francés, siempre descrita a partir de la Gramática de la lengua standar. El modelo abstracto del verso francés consistiría en un metro organizado de acuerdo con dos acentos fijos, uno sobre la rima y otro sobre la cesura (Delas y Filliolet 1981: 157). Puesto que la poesía asocia la estructura rítmica impuesta por la métrica a la estructura rítmica de la lengua ordinaria, es la distribución de los acentos lingüísticos en cada uno de los hemistiquios delimitados por la cesura lo que produciría los efectos perceptibles por el receptor lírico y lo que, por tanto, interesaría a esa Retórica del ritmo poético. Aunque esta especie de pre-pragmática del ritmo poético sigue 
demasiado supeditada a la Gramática Métrica que trata no tanto de la percepción de los elementos constitutivos del ritmo como de la forma en que éstos se organizan, se anuncia ya el que puede ser el futuro de los estudios métricos: una organización formal que implica determinados efectos significativos y pragmáticos que deben ser estudiados desde un nuevo enfoque metodológico.

\section{MÉTRICA, SEMIÓTICA Y PRAGMÁTICA DE LA POESÍA}

La introducción al presente trabajo terminaba con las reflexiones de José Domínguez Caparrós sobre la integración de la Métrica en una Teoría literaria general que venía a coincidir con la Semiótica literaria, es decir, con una forma de abordar la literatura en tanto que fenómeno de comunicación estética. En ese texto de singular importancia histórica para los estudios de Métrica en el contexto internacional, daba su autor no sólo la pista sino también la solución: considerar la métrica como una de las convenciones de la comunicación artística poética. Precisamente ponía Domínguez Caparrós (1985 en 1999: 20-21) punto final a su Conferencia en el I Colóquio Luso-Espanhol de Semiótica evocando a uno de los semiólogos más importantes del panorama europeo, Cesare Segre (1985: 74), cuando proponía considerar los esquemas métrico-rítmicos como códigos.

Más recientemente y en otro lugar planteé la necesidad de recuperar, en la investigación pragmática, la vieja noción semiótica de código, procedente de la teoría de la información y expuesta por Eco ya desde los años sesenta en toda su riqueza conceptual como sistema de sistemas semánticos y sintácticos, sus reglas combinatorias y circunstanciales que preveen las múltiples posibilidades comunicativas e interpretativas (Eco 1968, 1989: 122, Paz Gago 1999: 139 y ss.).

En mi propuesta de Pragmática del texto poético, en efecto, describí el funcionamiento de este tipo de textos en términos de la interacción en el poema entre los participantes en la comunicación lírica, regida por un complejo sistema de códigos textuales (retórico y rítmico-métrico fundamentalmente) y contextuales (culturales, sociales, históricos...). Esta Pragmática que coincide con el dominio global de la Semiótica (pragmáticamente orientada) en la formulación original 
de Peirce y que he denominado de tercera generación (1999: 15 t ss.) dará cuenta eficazmente del funcionamiento comunicacional del texto lírico si presta especial atención a los códigos que rigen su enunciación y su recepción. Se trata de los códigos rítmico-métrico ${ }^{2}$ y retórico, cuya acción sobre el código lingüístico básico es decisiva en la producción textual y particularmente efectiva en la recepción lírica. De ambos códigos dependen las particularidades textuales que, convencionalizadas e institucionalizadas, permiten a los lectores reconocer, interpretar adecuadamente y disfrutar la lectura del poema al experimentar sus esfectos estéticos propios.

Paralelamente a las propuestas métricas de los Formalistas eslavos, autores como E. W. Scripture (1929) en la Europa Occidental o W. Schramm (1935) en Norteamérica renovaban ya los estudios de Métrica inglesa aplicando criterios literalmente pragmáticos. El primero proponía una nueva noción de acento y de pie métrico basada en rasgos no sólo físicos sino también perceptivos, tales como un tono más alto, la ralentización o una pronunciación más precisa, todo lo cual implicaría una impresión específica y en consecuencia un efecto psicológico especial sobre el oyente. Muy avanzado incluso en sus propuestas tecnológicas, Schramm, por su parte, se fijó en la entonación entendida como tono musical y en la intensidad, que dividiría el flujo temporal del verso en breves intervalos, tratando de representar estos parámetros sobre una pantalla en el transcurso de la recitación poética.

El código rítmico-métrico posee una particular relevancia en la estructuración tanto formal como semántica del texto lírico, aunque no es exclusivo de él pues funciona también en la poesía épico-narrativa, dramática e incluso en otros tipos de textos publicitarios, litúrgicos... Su función consiste en imprimir al poema una disposición gráfica y textual específica para dotarlo de ritmo, ese especial efecto sonoro y musical que va dirigido a intensificar los efectos placenteros de la recepción poética. La disposición del poema en el centro de la página, con amplios espacios blancos a derecha e izquierda, propone ya al receptor la convención lírica de lectura. Puede revestir una gran rigidez normativa como ocurre en el caso de las reglas de disposición estrófica, versal y rimática de la décima o del soneto clásico; un carácter prescriptivo menos fuerte regula composiciones populares como el

2 Preferimos denominar así a un código muy complejo que, a efectos del análisis semiótico-textual, podría a su vez desarticularse en tres subcódigos: rimático, melódico y métrico, tal como hace Reis (1979: 289). 
romance, poema no estrófico formado por una serie ilimitada de versos con rima asonantada en los pares.

Tal como hicieron los formalistas rusos, es necesario integrar los aspectos métricos dentro de las estrategias rítmicas y, de hecho, este código puede basar su acción en factores rítmicos ajenos a la organización métrica, como sucede en el llamado verso libre, el cual puede prescindir de cualquier tipo de regularidad fónica. Cuando Eichenbaum (1925 en Volek ed. 1992: 94-95) señaló las aportaciones del método formal a los estudios métricos reclamó el abandono de la mera descripción para enfocar los principios del verso, entre los que situaba en primer lugar el ritmo a cuya producción contribuyen tanto los aspectos métricos propiamente dichos como otros aspectos esenciales al discurso poético.

La decisiva renovación teórica y práctica de la aproximación científica a los fenómenos métricos que puede aportar una perspectiva semiótica y pragmática pasa por su integración en los fenómenos más generales del ritmo, concepto esencialmente perceptivo. Era esa la tesis que exponía Domínguez Caparrós en una nueva e iluminadora aproximación al tema de la Métrica y los estudios literarios, una conferencia pronunciada esta vez en un lugar tan emblemático para la Semiótica española como la Universidad de Oviedo (1991): tras dejar sentado que las estructuras formales de la métrica tienen un evidente poder de creación de sentido (estético) y por tanto constituirán por derecho propio una parcela de esa ciencia literaria general que es la semiótica, exigía la consideración de la métrica y de su valor estético literario como fenómenos rítmicos (1992 en 1999: 93 y 98), fundamentando tales afirmaciones en la tradición Poética que va de Aristóteles a Zhirmuskij.

El ritmo poético o, mejor, el efecto rítmico es una propiedad sonora de los textos poéticos que puede lograrse mediante la aplicación del código métrico, cuyo núcleo central está constituído por las reglas de la versificación, de naturaleza esencialmente fónica, o mediante la utilización de otro tipo de elementos repetitivos, sintácticos y semánticos. Como hemos visto, en los primeros trabajos del formalismo eslavo se puso de manifiesto que el poema, según su orientación estética, explota diferentes factores rítmicos, desde los rasgos de naturaleza cuantitativa como el tono, el acento y la longitud hasta factores sonoros (rima, aliteraciones) o puramente verbales ( $c f r$. Erlich 1974: 318) ${ }^{3}$.

3 En concreto, los paralelismos o repeticiones de esquemas morfosintácticos, fónicos y semánticos constituyen mecanismos rítmicos muy utilizados por el versolibrismo, 
La versificación determina en primer lugar la disposición del texto en segmentos más breves que las líneas normales de la prosa, configuración gráfica que tiene ya consecuencias rítmicas y receptivas, claramente apreciables en su realización oral, recitada o cantada. El código rítmicométrico impone al texto, en efecto, normas ajenas e incluso opuestas a las del código linguístico como la disposición en versos y estrofas, el hipérbaton o las pausas métricas que suponen una violación consciente e intencional del sistema sintáctico en favor del factor rítmico.

El verso es, pues, una unidad rítmica y melódica, de modo que Navarro Tomás (1978: 35) lo definirá como serie de palabras cuya disposición produce un efecto musical. Es, en efecto, el portador de los diferentes factores del ritmo métrico: sílaba y cantidad silábica, acento y tono ${ }^{4}$. El ritmo no es más que el resultado de la repetición simétrica de esos factores pertinentes, situados en una proximidad espaciotemporal y en una relación de contraste ( $c f$. Domínguez Caparrós 1993: 34). Fenómeno esencialmente perceptivo, es esencial al efecto rítmico la temporalidad y el contraste, puesto que se trata de una configuración de elementos diferentemente marcados (largas/breves, fuertes/débiles, átonas/tónicas) que se repiten periódica y alternativamente en el tiempo. Esos condicionantes están presentes en la mayor parte de los intentos de definición del ritmo: desde los formalistas rusos, alternancia regular en el tiempo de fenómenos comparables ( $c f r$. Erlich 1974: 318), hasta los formalistas franceses, estructuración repetitiva secuencial de unidades en relación contrastiva (Molino y Tamine: 1982: 33), combinatoria secuencial jerarquizada de hechos discretos (Roubaud y Lusson 1978: 69-70, 1980). Pero desde esta perspectiva formalista no poco acertada, no se había puesto de relieve suficientemente la naturaleza pragmática del ritmo poético y su razón de ser esencialmente receptiva, es decir, comunicacional.

Valéry (1991, I: 1283 y ss.) hacía radicar las propiedades formales y semánticas del ritmo en la periodización secuencial de las unidades en

a los que prestaron una atención especial Brik, Jakobson o Levin en su difundido trabajo sobre los coupling. En Lingüística y Poética (1958), Jakobson consideraba el paralelismo gramatical como el procedimiento fundamental de la poesía, invocando el postulado de Hopkins según el cual todo artificio en poesía se resumiría en el principio de paralelismo (1980: 107).

4 Como es bien sabido, la versificación española explota dos de estos factores, dando lugar a un sistema mixto sílabo-acentual definido por el cómputo silábico y el acento de intensidad. Este doble sistema ha llevado a dos interpretaciones de la métrica hispánica que se basaría o bien en la oposición entre sílabas tónicas y sílabas átonas o bien se consideran éstas como pies o cláusulas en las que se interpreta la sílaba acentuada como larga y la no acentuada como breve. 
contraste que generan una dinámica de espera: el receptor, en situación espectante, percibiría cada unidad distinta como respuesta a la unidad antecedente (Zilberberg 1996: a2-a5). Este mecanismo daría al ritmo una dimensión tensiva a la que seguiría un momento de distensión indisolublemente unida al propio efecto rítmico que, de este modo, resulta placentero. Es en este contexto pragmático en el que ha sido reinterpretado el ritmo propio del texto lírico como un fenómeno sonoro y musical unido intrínsecamente al efecto poético de naturaleza sensorial y emocional que debe experimentar el lector del poema (Paz Gago 1999: 130 y ss.). No en vano Navarro Tomás (1978: 27-28) mantuvo la concepción musical según la cual los versos se componen de períodos rítmicos semejantes a compases musicales, marcados por el acento de las sílabas que vendrían a considerarse como notas musicales.

Si ya Valéry veía el ritmo como un fenómeno de intercambio (1991, I: 1282), es fundamental para la perspectiva pragmática poner de relieve la naturaleza perceptiva del ritmo poético y del código rítmicométrico que regula su producción con la finalidad exclusiva de provocar determinados efectos sonoros y musicales, sensoriales y placenteros, en el receptor lírico. Frente a la prosa, en el texto versificado el lector espera, prevee, esa percepción de repeticiones rítmicas de forma que la lectura del poema viene motivada y guiada por esas expectativas, que son también las previsiones del enunciador textual para un lector potencial y cooperativo. La percepción de los fenómenos rítmicos manifestados desde la disposición gráfica y materializados por las normas métricas y otros procedimientos como la estructuración paralelística y las isofonías generalizadas, es parte esencial de la recepción pues, como piensa Domínguez Caparrós (1988a:75-76. 1993: 38), confirma o frustra las expectativas del receptor.

El efecto fónico-melódico en que consiste el ritmo es un efecto sensorial placentero intrínsecamente vinculado con los efectos musicales, hasta tal punto que Wagner llegaba a afirmar que la música sólo era perceptible a través del ritmo (cit. en Escal 1996: e1). De hecho, tanto la música como la poesía comparten ese factor temporal que contribuye decisivamente a desencadenar el placer de la repetición, esa sensación rítmica placentera que acompaña la audición musical, el canto o la simple recitación de la lírica. Recuperamos así el espíritu original de la teoría métrica de Tomás Navarro Tomás, en donde se interpretaba el ritmo versal de acuerdo con los mismos principios que el ritmo de la música y el canto (1978: 35) pues la única finalidad de la versificación es producir los efectos musicales. No debemos olvidar que la poesía 
considerada como no mimética en la Poética clásica, la mélica, era poesía cantada, con o sin acompañamiento de instrumentos musicales $\mathrm{y}$, del mismo modo, se ha dicho con frecuencia que la canción moderna, del pop al rock, es la auténtica poesía lírica de hoy.

Aglutinar metro y ritmo resulta adecuado para configurar un código complejo, pero ambos factores no se confunden: El metro o medida es una organización rígida en la que las unidades están contabilizadas y codificadas estrictamente, mientras que el ritmo puede conseguirse por medios más aleatorios y flexibles. Ya habían aparecido en la Antigüedad griega esos dos sentidos del $\rho v \zeta \mu o \sigma:$ tanto algo que se mueve, fluye, cambia... como el movimiento del cuerpo en la danza, sujeto a la medida y al número, al metro, que es la significación preferida por Platón. Las teorías métricas del Renacimiento establecieron la oposición terminológica entre el metro, consecuencia del número de sílabas, y el ritmo conseguido por la distribución de los acentos en pies métricos, dicotomía que ha llegado hasta la Semiótica literaria actual ${ }^{5}$.

La medida regular y la medida fluctuante o libre, metro y ritmo, contribuyen de igual modo a producir los efectos rítmicos, razón por la cual ambos fenómenos forman parte de un mismo código esencial al peculiar proceso de la comunicación poética, independientemente de la mayor o menor rigidez normativa de ese código ${ }^{6}$. En efecto, la poesía necesita a la vez un imprescindible sistema de reglas y un margen de variabilidad, el metro y el ritmo propiamente dicho, pues ambos factores contribuyen a establecer la convención rítmica y a hacer experimentar el efecto estético y emocional en una satisfactoria recepción lírica.

Estas notas finales esbozan un camino prometedor apenas iniciado en estas páginas, el camino que sugería José Domínguez Caparrós al señalar que la semiótica literaria nos puede proporcionar el marco teórico mejor pertrechado para integrar los diversos aspectos de la función literaria de la métrica (1991 en 1999: 103). Para este replanteamiento de gran calado metodológico y de vital trascendencia tanto

${ }^{5}$ En tales criterios basa por ejemplo Zilberberg (1985: 33-34. 1988: 137-138) su distinción entre lo métrico y lo rítmico, que le lleva a interpretar la perspectiva silábica de Jakobson como métrica y la de Hopkins, que ignora el papel del cómputo silábico, como rítmica.

6 A partir de la herencia clásica, los musicólogos distinguen entre el ritmo o producción no isocrónica de acentos y el metro, repetición de acentos isócronos, que fundamentaría la oposición entre la música que se baila, basada en el metro regular, y la música que se escucha, cuyo ritmo se basaría en movimientos de duración libre y desiguales (Escal 1996: c2-c3. Cfr. E. Benveniste, «La notion de rythme dans son expression linguistique», (Problèmes de Linguistique Générale, Paris: Gallimard, 1966: 333-334). 
para los estudios literarios como para los estudios de Métrica del presente y del futuro invocaba Domínguez Caparrós los parámetros ofrecidos por una de las figuras más destacadas de la semiótica española, Carmen Bobes Naves (1989: 77 y ss.) cuando contextualizaba la Métrica descriptiva dentro de la Sintaxis semiótica, el valor simbólico e icónico de la versificación en el seno de la Semántica semiótica y, tal como he propugnado aquí, las muchas implicaciones de tipo sociológico y cultural de la Métrica en el marco de la Pragmática.

\section{Referencias bibliográficas}

BeAVER, J. C. (1968). «Progress and Problems in Generative Metrics». En Papers from the Fourth Regional Meeting Chicago Linguistic Society, Darden, B. J. et al. (eds.). Chicago: University of Chicago Press, 146-155.

- (1969). «Contrastive Stress and Meterd Verse». Language and Speech, 2: $257-271$.

- (1974). «Generative Metrics: the Present Outlook». Poetics, 12, 7-28.

Bobes NaVes, M. C. (1989). La semiología. Madrid: Síntesis.

- (1994). «La semiología en España». En Retos actuales de la Teoría Literaria, Paraíso, I. (ed.). Valladolid: Universidad de Valladolid, 11-30. Bowley, C. C. (1974), «Generative Metrics». Poetics 12, 7-28.

CORNULIER, B. de (1982). Théorie du vers. Rimbaud, Verlaine, Mallarmé. Paris: Seuil.

- (1986). «Versifier: le code et sa règle». Poétique 66, 191-197.

- (1993). «Le système classique des strophes». Métrique française et métrique accetuelle, Langue Française 99, 26-44.

Chatman, S. (1960). "Comparing Metrical Styles». En Style in Language, Sebeok, T. A. (ed.). New York: MIT Press, 149-172.

- (1965). A Theory of Meter, The Hague: Mouton.

Chatman, S. and Levin, S. R. (1965). «Linguistics and Poetics». En Encyclopedia of Poetry and Poetics, Preminger, A. (ed.). Princeton: Princeton University Press.

- (1973). «Linguistics and Literature». En Currents Trends in Linguistics, vol. 10. Linguistics in North America, Sebeok, T. A. (ed.). The Hague: Mouton, 250-294.

Chomsky, N. \& Halle, M. (1968). The Sound Pattern of English. New York: Harper \& Row.

DinU, M. (1993). «Structures accentuelles de l'alexandrin chez Racine». En Métrique française et métrique accetuelle, Langue Française 99, 63-73.

Domínguez CAPARRós, J., (1975). Contribución a la historia de las teorías métricas en los siglos XVIII y XIX. Madrid: CSIC. 
- (1985). Diccionario de métrica española. Madrid: Paraninfo, $2 .^{a}$ ed. 1992.

- (1987). «Métrica y Semiótica». En Da semiotica. Lisboa: Vega S.A., 201-209. En 1999: 11-22.

- (1988a). Métrica y Poética. Bases para la fundamentación de la Métrica en la Teoría literaria moderna. Madrid: UNED.

- (1992). «La métrica y los estudios literarios». Epos 8, 245-260. En 1999: 91-109.

- (1993). Métrica española. Madrid: Síntesis.

- (1999). Estudios de métrica. Madrid: UNED.

Eichendaum, B. (1922). El principio melódico del verso. Petrogrado: Opojaz.

- (1925). «La teoría del método formal». En Literatura: Teoria, Kritika, Polemica, Leningrado: Proboi, 1927, 116-148. Ed. esp.: Antología del Formalismo Ruso y del Círculo de Bajtin, Volek, E. (ed.), 1992: 69113.

ERLICH, V. (1969). Russian Formalism. History. Doctrine. The Hague: Mouton. Ed. española: Barcelona: Seix Barral, 1974.

ESCAL, F. (1996). «Mètre, rythme, structura musicale». Degrés 78, e 1- e 16. FOWLER, R. (1966a). «Prose Rhythm and Meter». En Essays on Style and Language: Linguistic and Critical Approaches to Literary Style, Fowler, R. (ed.). London: Rotledge and Kegan Paul, 82-99.

- (1966b). «Structural Metrics». Linguistics 27, 49-64.

- (1968). «What is Metrical Analysis?». Anglia 86, 280-320.

- (1970). «Prose, Rythm and Meter». En Linguistics and Literary Style, Freeman, D. C. (ed.), 347-365.

- (1976). «Metrics and the Transformational-Generative Model». Lingua 38, 21-32.

- (1977). «Comparative Metrics and Comparative Literature». Comparative Literature 29, 289-299.

FreEman, D. C. (1968). «On the Primes of Metrical Style». En Language and Speech 1, 63-101.

- (1969). «Metrical Position Constituency and Generative Metrics», Language and Speech 2, 195-206.

Grimaud, M. (1992). «Versification and its Discontents: Toward a Research Program». Semiotica 88, 3/4, 199-242.

- (1993). «Tools for the Study of Verse». Empirical Studies of the Arts $11 / 1,79-82$.

Grimaud, M. de (1992a). Pour une métrique du vers hugolien. Paris: Minard.

- (1992b). «Foundations of Verse». Empirical Studies of the Arts 10/2.

GRIMAUD, M. y BALDWIN, L. (1993). «Versification cognitive: la strophe». Poétique 95, 259-276.

GuÉRON, J. (1974). «The Meter of Nursey Rhymes: An Application of the Halle-Keyser Theory of Meter». Poetics 12, 73-111. 
GuIRAUD, P. (1965). «L'esthétique du vers français». Revue d'Esthétique 3-4. - (1970). La versification, Paris: PUF.

Halle, M. (1970). «On Meter and Prosody». En Progress in Linguistics: A Colletion of Papers. Bierwisch, M. y Heidolph, K. E. (eds.). The Hague: Mouton, 64-80.

- (1995a). «An Orally Transmitted Poem of Mayakovsky». En Studies in Poetics: Commemorative Volume Krystina Pomorska 1928-1986, Semeko-Pankratov, E. (ed.). Columbus: Slavica Publ., 275-276.

- (1995b). «Stress Placement in Russian Nouns». En O Rus! Studia Literaria Slavica in Honorem Hugh McLean, Karlinsky, S. et al. (eds.). Berkeley: Berkeley Slavic Specialties, 106-115.

- (1997a). «On Stress and Accent in Indo-European». Language 73, 275-313.

- (1997b). «Metrical Verse in the Psalms». En India and Beyond: Aspects of Literature, Meaning, Ritual and Thought. Essays in Honour of Fritz Staal, Meij, D. van der (ed.). London: International Institute for Asian Studies - Kegan Paul, 207-225.

Halle, M. and Idsardi, J. W. (1994). "General Properties of Stress and Metrical Structure». En The Handbook of Phonological Theory, Goldsmith, J. (ed.). Oxford and Cambridge (MA): Blackwell, 403-443.

Halle, M. and Keyser, J. (1966). «Chaucer and the Study of Prosody», College English 28, 187-219.

- (1971). «Illustration and Defense of a Theory of Iambic Pentameter», College English 33, 154-176.

- (1998). «On Meter in General and on Robert Frost's loose Iambics in Particular». En Festschrift for Professor K. Inoue, Iwamoto, E. (ed.). Kanda University of International Studies.

Halle, M. and Vergnaud, J. R. (1990). An Essay on Stress. Chicago: The MIT Press Books.

HasCALL, D. (1969). «Some Contributions to the Halle-Keyser Theory of Prosody». College English 30, 357-365.

- (1974). «Triple Meter in English Verse». Poetics 12, 49-71.

HAYEs, B. (1980). A Metrical Theory of Stress Rules, Doct. diss. Cambridge (MA): MIT.

- (1988). «Metrics and Phonological Theory». En Linguistics: The Cambridge Survey, Newmeyer, F. J. (ed.). Cambridge: Cambridge University Press, vol. II, 220-249.

Hollander, J. (1959). «The Metrical Emblem». Kenyon Review, 21: 279-296.

- (1961). «Experimental and Pseudo-experimental Metrics in recent American Poetry». Poetics, 127-135.

- (1970). «The Romantic Metrical Contract». En Romanticism and Consciousness: Essays in Criticism, Bloom, H. (ed.). New York: Norton.

- (1990). Rhyme's Reason: A Guide to English Verse. New Haven: Yale University Press. 
IHWE, J. F. (1975). «On the Foundations of «Generative Metrics»». Poetics, $16,367-399$.

JAKOBSON, R. (1923). O cheshskom stije: Sborniki po teorii poeticheskogo iazyka (Sobre el verso checo). Ed. parc. fr.: «Principes de versification». En Questions de Poétique, Todorov, T. (ed.). Paris: Seuil, 1973, 40-55.

- (1933). «Über den Versbau der Serbokroatischen Volksepen». ANPE. 7-9, 44-53.

- (1935). «The Dominant». En Readings in Russian Poetics, Matejka, L. y Pomorska, K. (eds.), 82-87. Ed. ingl.: Cambridge and London, 1971.

- (1952). «Studies in Comparative Slavic Metrics». Oxford Slavonic Papers 3, 21-66.

- (1960). «Closing Statements: Linguistics and Poetics». En Style in Language, Sebeok, T.A. (ed.). New York: Technology Press Wiley 350-377. Ed. fr.: Essais de Linguistique Générale. Paris: Minuit, 1963. Ed. esp.: Barcelona: Seix Barral, 1975 y Madrid: Cátedra, 1974.

- (1973). Questions de poétique. Paris: Seuil. Ed. esp.: México: Fondo de Cultura Económica, 1977.

- (1979). Selected Writings. V. On Verse, Its Masters and Explorers, Rudy, S y Taylor, M. (eds.). The Hague: Mouton.

- (1981). Lingüística, poética, tiempo.Conversaciones con Krystina Pomorska. Barcelona: Crítica.

- (1985). Verbal Art, Verbal Sign, Verbal Time, Pomorska, K. y Rudy, S. (eds.). Minneapolis: University of Minnesota Press.

JAKOBSON, R. and LOTZ, J. (1952). «Axioms of a Versificatiom System Exemplified by the Mordvinian folksong». Acta Instituti Hungarici Universitatis Holmiensis, Series B. Linguistics 1, 5-13.

Keyser, S. J. (1969a). «The Linguistics Basis of English Prosody». En Modern English Studies, Reibel, D. A. y Schane, S. (eds.). Englewood Cliffs: Prentice-Hall, 379-394.

- (1969b). «Old English Prosody». College English 30, 331-356.

- (1973). «Vers une théorie de la forme et du sens en poésie». Change 16-17, 154-187.

KIPARSKY, P. (1977). «The Rythmic Structure of English Verse». Linguistic Inquiry, 8: 189-247.

KLEIN, W (1974). «Critical Remarks on Generative Metrics». Poetics 12, 29 48.

Levin, J. (1985). A Metrical Theory of Syllabicity, Doct. diss. Cambridge (MA): MIT.

LEVIN, S. R. (1962). Linguistic Structures in Poetry. The Hague: Mouton. Ed. esp.: Madrid: Cátedra, 1974. 3. ${ }^{\mathrm{a}}$ ed. 1979.

- (1976). «A Revision of Halle-Keiser Metrical Theory». Language 49/3, 606-611.

LOTZ, J. (1942). «Notes on Structural Analysis in Metrics». Helikon 4, 119-146.

- (1960a). «Metrics and Linguistic Analysis». Monograph Series on Language and Linguistics 12, 129-137. 
- (1960b). «Metric Typology». En Style in Language, Sebeok, T.A. (ed.). Cambridge (Mass.): MIT Press, 135-148.

- (1974a). "Metrics», Currents Trends in Linguistics, vol 13. Current Trends in the Historiography of Linguistics, Sebeok, T. A. (ed.). The Hague: Mouton, 963-968.

- (1974b). «Elements of Versification». Versification: Mayor Language Types, Wimsatt, W. K. Jr. (ed.), 1-21.

Molino, J. y TAMINE, J. (1982). Introduction à l'analyse linguistique de la poésie. I. Vers et figures. Paris: PUF. 2. ${ }^{\mathrm{a}}$ ed., 1987.

- (1988). Introduction à l'analyse linguistique de la poésie. I. De la strophe à la construction du poème. Paris: PUF.

NAVARro TOMÁs, T. (1956). Métrica española: reseña histórica y descriptiva. Syracuse: Syracuse University Press. 3. ${ }^{\mathrm{a}}$ ed. 1978.

NúÑEZ RAMOS, R. (1978). «Para un modelo abstracto del endecasílabo castellano». Dispositio 3-7/8, 157-165.

- (1992). La poesía. Madrid: Síntesis.

OTERo, C. P. (1981). «Una métrica de nueva planta». Verba 8, 307-320.

OLIVA, S. (1980). Métrica catalana. Barcelona: Edicions dels Quaderns Crema.

Paz Gago, J. M. (1999). La recepción del poema. Pragmática del texto poético. Kassel: Reichenberger.

PIERA, C. (1978). On Accentual-Syllabic Metrics: The Spanish Hendecasyllable. Chicago: MIT (manuscrito).

- (1981). Spanish Verse and the Theory of Meter, Dissertation Abstracts International (42/1). Chicago: MIT.

PRIETO Alonso, D. (1983). Structures métriques: la métrique accentuelle périodique galicienne. Groningen: Universidad de Groningen (Tesis inédita).

- (1984). «Estructura métrica da moiñeira». Grial 84, 131-153.

- (1986). «A métrica rítmica en Rosalía». En Actas do Congreso Internacional de Estudios sobre Rosalía de Castro e o seu tempo. Santiago de Compostela: Consello da Cultura Galega-Universidad de Santiago, vol. II: 383-400.

Roubaud, J. (1971). «Mètre et vers». Poétique 7, 366-387.

- (1986). La fleur inverse. Essai sur l'art formel des troubadours. Paris: Ramsay.

Ruwet, N. (1972). Langage, Musique, Poésie. Paris: Seuil.

- (1979). «Blancs, rimes et raisons. Typographie, rimes et structures linguistiques en poésie». Revue d'Esthétique 1-2, 397-425.

SCHMIDT, S. J. y BARSCH, A. (1981). Generative Phonologie und Generative Metrik: Rekonstruktive Untersuchungen auf der Grenze Zwischen Linguistik und Literaturwissenschaft. Opladen: Forschung Westdeutscher.

Schramm, W. L. (1935). Approaches to a Science of English Verse. Iowa City: State University of Iowa.

SCRIPTURE, E. W. (1929). Grundzüge der Englischen Verswissenschaft. Marburg: N. G. Elwert. 
SEgRe, C (1985). Avviamento all' analisi del testo letterario. Torino: Einaudi. Ed. esp.: Principios de analisis del texto literario. Barcelona: Crítica, 1985.

TOMACHEVSKI, B. (1923). «El problema del ritmo en el verso». En Literaturnaia Mysl', vol. 2.

- (1924). Russkoie stijozlozshenie (La versificación rusa).

Thomas, J. J. (1989). «Teoría generativa y Poética literaria». En Poética Generativa. Buenos Aires: Hachette, 9-83.

Tynianov, J. (1924). Problema stijotvornogo iazyka, Leningrado: Akademia. Ed. esp.: El problema de la lengua poética. Buenos Aires: Siglo XXI, 1972. - (1977). Le vers lui-même. Paris: Editions 10/18.

Whitehall, H. (1951). «From Linguistics to Criticism». Kenyon Review 13, 710-714.

Whitehall, H. and Hitl, A. A. (1958). «A Report on the Language-Literature Seminar». En Readings in Applied English Linguistics, Allen, H. B. (ed.). New York: Appleton Century Crofts, 488-492.

WimsatT, W. K. Jr. (1970). «The Rule and the Norm: Halle and Keyser on Chaucer's Meter». College English 31, 774-788.

WIMSATT, W. K. Jr. (ed.) (1974). Versification: Mayor Language Types. New York: New York University Press.

WimsatT, W. K. Jr. y BeARDSLey, M.C. (1959). «The Concept of Meter: an Exercise in Abstraction». PMLA 74, 585-598.

ZhIRMunski, V. (1919). «The Task of Poetics». En Selected Writings. Linguistics. Poetics. Moscow: Progress Publisher, 1985: 261-319.

- (1921). Kompozitsia liricheskij stijotvorenii (La composición de los poemas líricos). Petrogrado: Opojaz.

- (1925). Vvedenie o metriku. Ed. ingl.: Introduction to Metrics. The Theory of Verse. The Hague: Mouton, 1966.

- (1975). Teorija sticha (Teoría del verso). Leningrado.

ZILBERBERG, Ch. (1985). L'essor du poème. Information rythmique. SaintMaure: Phoriques.

- (1988). Raison et poétique du sens. Paris: PUF.

- (1996). «Signification du rythme et rithme de la signification». Degrés 87, a 1-a 25. 